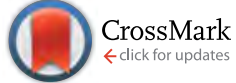

Cite this: RSC Adv., 2016, 6, 88826

\title{
Sugarcane molasses as a pseudocapacitive material for supercapacitors $\dagger$
}

\author{
A. Sanchez-Sanchez, ${ }^{\text {aa }}$ Alicia Martinez de Yuso, ${ }^{a}$ Flavia Lega Braghiroli, ${ }^{a}$ \\ M. Teresa Izquierdo, ${ }^{b}$ Edelio Danguillecourt Alvarez, ${ }^{d}$ Eduardo Pérez-Cappe, ${ }^{c}$ \\ Yodalgis Mosqueda, ${ }^{c}$ Vanessa Fierro ${ }^{\star a}$ and Alain Celzard ${ }^{a}$
}

Oxygen-rich carbons were obtained from sugarcane molasses by two methods: direct carbonisation on one hand, and hydrothermal carbonisation and subsequent pyrolysis on the other hand. As no activation treatments were applied, the porous texture was poorly developed and mainly composed of ultramicropores with restricted access to electrolyte ions. Despite this, the directly carbonised molasses exhibited specific capacitances up to $153 \mathrm{~F} \mathrm{~g}^{-1}$ at $0.5 \mathrm{mV} \mathrm{s}^{-1}$ in $1 \mathrm{M} \mathrm{H}_{2} \mathrm{SO}_{4}$ electrolyte when tested as electrodes in a three-electrode system. Given the low specific surface areas of the carbons, the capacitance values were mainly assigned to their pseudocapacitance contributions. The latter were more adequately estimated by considering the NLDFT surface area $\left(S_{\text {NLDFT }}\right)$ than the BET area $\left(A_{\mathrm{BET}}\right)$ due to the narrow porosity of the materials. Maximum values of pseudocapacitance contribution of $35.2 \%$ were attained for the carbon with a $S_{\text {NLDFT }}$ of $178 \mathrm{~m}^{2} \mathrm{~g}^{-1}$, which were explained by the high concentrations of surface oxygen groups, such as quinones and carbonyls.

Received 23rd June 2016

Accepted 10th September 2016

DOI: $10.1039 / c 6 r a 16314 a$

www.rsc.org/advances which the energy is stored through the charge separation at the electrode/electrolyte interface, designated as EDLC mechanism; (ii) pseudocapacitors, wherein the energy is stored through faradaic reactions taking place at the electrode surface, designated as pseudocapacitance.

Carbon materials can store energy through both mechanisms, and different types of carbon, such as activated carbons, carbon nanotubes, mesoporous carbons, carbon nanofibers, graphene, etc., have been intensively investigated to be used as electrodes for supercapacitors. ${ }^{4}$ Using carbon materials containing surface functionalities (O, N, P, B or S functional groups) has been an attractive strategy to increase the energy density of supercapacitors by promoting the pseudocapacitive storage mechanism. ${ }^{5-9}$ Moreover, the presence of functional groups in the material surface both improves electrode wettability and modifies the electronic and acid-base properties of the surface, thereby affecting the capacitance and, hence, the energy density. ${ }^{8}$ For instance, oxygen-doped carbons show enhanced specific capacitances with respect to their non-doped counterparts in aqueous electrolytes. ${ }^{\mathbf{1 0}}$ Depending on the acidic or basic character of the electrolyte, different oxygen functionalities are involved in pseudocapacitance, namely quinones, carbonyls, phenols or carboxylic acids. ${ }^{11}$ The functionalisation of carbon surface with oxygen groups is usually performed through wet, dry, plasma or electrochemical oxidation post-treatments. ${ }^{12}$ However, these treatments are time-consuming procedures and a specific control of the type of the generated oxygen functionalities is hardly achievable.

A possible alternative to surface functionalisation is based on the use of oxygen-containing precursors such as biomass-derived Quimica, Holguín 83300, Cuba

$\dagger$ Electronic supplementary information (ESI) available. See DOI: 10.1039/c6ra16314a

${ }^{a}$ Institut Jean Lamour, UMR CNRS-Université de Lorraine no. 7198, ENSTIB, 27 Rue Philippe Séguin, 88026 Epinal Cedex, CS 60036, France. E-mail: angela. sanchez-sanchez@univ-lorraine.fr; Vanessa.Fierro@univ-lorraine.fr; Tel: +33 329 ${ }^{b}$ Instituto de Carboquimica, ICB-CSIC, Miguel Luesma Castan, 4, 50018 Zaragoza, Spain

'Institute of Materials Science and Technology (IMRE), Havana University, Zapata y G, Vedado, Havana 10400, Cuba

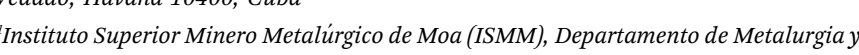


materials. In this sense, hydrothermal carbonisation (HTC) has received growing interest because it is an easy method, applying low temperature and environment-friendly conditions, to obtain oxygen-rich hydrochars from biomass precursors. ${ }^{13,14}$ But hydrochars exhibit generally not enough open porosity and carbonisation at high temperatures only produces a slight increase of their textural properties. Therefore, chemical activation is often used to develop their porosity, thereby increasing the electric double-layer capacitance. ${ }^{\mathbf{6} 15-17}$ Many activated carbons obtained by $\mathrm{KOH}$ chemical activation of biomass precursors have indeed shown excellent performances as electrode materials in supercapacitors with different electrolytes. As examples, waste dragon fruit skin, Momordica grosvenori skin and Firmiana catkins exhibited specific capacitances exceeding $230 \mathrm{~F} \mathrm{~g}^{-1}$ at $0.5 \mathrm{Ag}^{-1}$ in a three-electrode cell with $2 \mathrm{M} \mathrm{KOH}$ electrolyte, ${ }^{18}$ activated carbons obtained from rice brans yielded specific capacitances of $265 \mathrm{~F} \mathrm{~g}^{-1}$ at $10 \mathrm{~A} \mathrm{~g}^{-1}$ in a two-electrode cell with $6 \mathrm{M} \mathrm{KOH}$ electrolyte, ${ }^{19}$ and activated carbons obtained by HTC of cellulose, potato starch and eucalyptus wood sawdust allowed obtaining specific capacitances up to $236 \mathrm{~F} \mathrm{~g}^{-1}$ at $1 \mathrm{mV} \mathrm{s}^{-1}$ in a twoelectrode cell with tetraethyl ammonium tetrafluoroborate $\left(\mathrm{TEABF}_{4}\right)$ /acetonitrile (AN) electrolyte. ${ }^{13}$ Even though higher specific capacitances are obtained after activation processes, it should be recalled that activation processes are time consuming and may generate toxic wastes..$^{20,21}$

Herein, we report the synthesis of carbon materials produced from sugarcane molasses, either by direct carbonisation on the one hand, or by HTC followed by pyrolysis on the other hand. A carbon material obtained by HTC of commercial sugar was also reported for comparison. The as-obtained carbons were tested as electrodes for supercapacitors in $1 \mathrm{M}$ $\mathrm{H}_{2} \mathrm{SO}_{4}$ electrolyte, without any activation or functionalisation post-treatment. A thorough study of both porosity and surface chemistry of the materials was carried out, and some correlation with their electrochemical performances was looked for. Surprisingly, the molasses-derived carbons possessing the lowest surface areas but the highest oxygen concentrations exhibited the highest specific capacitances. The pseudocapacitance contribution to the total capacitance was therefore estimated and a correlation between the surface chemistry and the specific capacitance of the materials was evidenced.

\section{Experimental}

\section{A. Materials}

Sugarcane molasses, i.e., the industrial viscous by-product of the refining of sugarcane into sugar, was supplied by the company "Cristino Naranjo" (Cacocum, Cuba). PTFE binder and carbon black powder used to fabricate the electrodes were both purchased from Sigma-Aldrich. The glass fibre separator was purchased from Pall Life Sciences. All the products were used as received.

\section{B. Material synthesis}

Hydrothermally-treated samples were prepared from molasses and sucrose solutions. In this work, different amounts of molasses $(2.57 \mathrm{~g})$ or sucrose $(2 \mathrm{~g})$ were used in order to have the same carbon content, and were dissolved in $16 \mathrm{~g}$ of water. The resultant solutions were then submitted to hydrothermal treatment in a Teflon-lined autoclave $\left(50 \mathrm{~cm}^{3}\right)$ under autogenous pressure $\left(180{ }^{\circ} \mathrm{C}, 24 \mathrm{~h}\right)$. The as-obtained product was filtered, washed several times with distilled water and dried in a vacuum oven $\left(80{ }^{\circ} \mathrm{C}, 12 \mathrm{~h}\right)$, and was called $\mathrm{MH}$ or $\mathrm{SH}$ depending on the carbon precursor, molasses or sucrose, respectively. Finally, $\mathrm{MH}$ and $\mathrm{SH}$ were carbonised under nitrogen flow ( $80 \mathrm{~mL} \mathrm{~min}^{-1}$ ) up to the final temperature (750 or $900{ }^{\circ} \mathrm{C}, 3 \mathrm{~h} ; 1^{\circ} \mathrm{C} \mathrm{min}^{-1}$ ), and subsequently cooled down to room temperature. The resultant carbons were named $\mathrm{MH}-\mathrm{T}$ and $\mathrm{SH}-$ $T$, where $T$ indicates the carbonisation temperature.

Molasses was also directly carbonised under nitrogen flow in the same conditions as for the hydrothermally treated samples (750 or $900{ }^{\circ} \mathrm{C}, 3 \mathrm{~h} ; 1{ }^{\circ} \mathrm{C} \mathrm{min}^{-1}$ ). The obtained carbons were designated as $\mathrm{M}-T, T$ being again the final carbonisation temperature $\left(750\right.$ or $\left.900{ }^{\circ} \mathrm{C}\right)$.

\section{Physicochemical and electrochemical characterisation}

Porous texture characterisation of the samples was performed by $\mathrm{N}_{2}$ and $\mathrm{Kr}$ adsorption at $-196{ }^{\circ} \mathrm{C}$ and by $\mathrm{CO}_{2}$ adsorption at $0{ }^{\circ} \mathrm{C}$ using an ASAP 2020 (Micromeritics) automatic equipment. Carbons and hydrochars were degassed for $48 \mathrm{~h}$ prior to any gas adsorption at $250{ }^{\circ} \mathrm{C}$ and at $60{ }^{\circ} \mathrm{C}$, respectively. The surface area was calculated through two methods: (i) the Brunauer-EmmettTeller (BET) model applied to the nitrogen adsorption data in the appropriate range of relative pressures, leading to $A_{\mathrm{BET}}$, and (ii) the Non-Local Density Functional Theory (NLDFT) model applied to the adsorption data obtained from both nitrogen and carbon dioxide isotherms, leading to $S_{\text {NLDFT }}$. The micropore volume was also determined by two methods: (i) from the Dubinin-Radushkevich (DR) equation, applied to the adsorption branches of nitrogen and carbon dioxide isotherms, leading to $V_{\mathrm{DR}-\mathrm{N}_{2}}$ and $V_{\mathrm{DR}-\mathrm{CO}_{2}}$, respectively, and (ii) from the NLDFT model, applied to the adsorption data obtained from nitrogen and carbon dioxide isotherms, leading to $V_{\mu \text {-NLDFT. }}{ }^{22}$ The total pore volume was calculated from the amount of nitrogen adsorbed at the relative pressure of $0.97, V_{0.97, \mathrm{~N}_{2}}$, and also from the pore size distributions (PSDs) calculated by applying the NLDFT model, $V_{\mathrm{T} \text {-NLDFT }}$. The mesopore volume $\left(V_{\text {meso }}\right)$ was determined by subtracting $V_{\mu \text {-NLDFT }}$ from $V_{\text {T-NLDFT }}$.

Thermogravimetric (TG) analyses were carried out in a STA 449F3 Jupiter (NETZSCH) microbalance by heating the samples $(\sim 20 \mathrm{mg})$ under argon flow up to the target temperature $\left(1000{ }^{\circ} \mathrm{C}, 10{ }^{\circ} \mathrm{C} \mathrm{min}^{-1}\right)$. Molasses moisture content was gravimetrically determined through the AOAC official method 925.04, by submitting the sample ( $\sim 1 \mathrm{~g})$ to a thermal treatment $\left(105{ }^{\circ} \mathrm{C}, 24 \mathrm{~h}\right)$ and subsequent cooling down to room temperature. Mineral ash content was gravimetrically evaluated using the AOAC official method 492.05, after calcination in $\operatorname{air}\left(550^{\circ} \mathrm{C}, 24 \mathrm{~h}\right)$ and cooling down to room temperature of the molasses sample ( $\sim \mathrm{g})$.

Temperature-programmed desorption (TPD) experiments were carried out in the aforementioned microbalance by submitting the sample $(0.3 \mathrm{~g})$ to a thermal treatment $\left(1100{ }^{\circ} \mathrm{C}\right.$, 
$\left.10{ }^{\circ} \mathrm{C} \mathrm{min}{ }^{-1}\right)$ in argon flow $\left(30 \mathrm{~mL} \mathrm{~min}^{-1}\right)$. The released gases, $\mathrm{CO}$ and $\mathrm{CO}_{2}$, were analysed in continuous mode with a QMS 403D Aëolos (NETZSCH) mass spectrometer. The calibrations for $\mathrm{CO}$ and $\mathrm{CO}_{2}$ were carried out by using the corresponding standard gases diluted in argon.

Scanning electron microscopy (SEM) and energy-dispersive X-ray spectroscopy (EDS) were performed with a FEI-NOVA NANOSEM 230 microscope coupled with an EDAX-Ametek detector. X-ray diffraction (XRD) patterns were obtained with a Bruker D8 Advance diffractometer in the following conditions: $\mathrm{Cu}-\mathrm{K} \alpha$ radiation; scanning range $2 \theta=2-80^{\circ}$; step width $=0.02^{\circ}$.

Bulk chemical composition of the materials (carbon, hydrogen, nitrogen and sulphur) was determined with a ThermoFlash 1112 apparatus. Surface chemical composition was analysed through X-ray photoelectron spectroscopy (XPS) by using an ESCAPlus OMICRON system equipped with a hemispherical electron energy analyser. The spectrometer was operated at $10 \mathrm{kV}$ and $15 \mathrm{~mA}$, using a non-monochromatised $\mathrm{Mg}-\mathrm{K} \alpha \mathrm{X}$-ray source $(h \nu=1253.6 \mathrm{eV})$ and under vacuum $(<5 \times$ $10^{-9}$ Torr). Analyser pass energy of $50 \mathrm{eV}$ was used for survey scans and $20 \mathrm{eV}$ for detailed scans. The C1s peak at $284.5 \mathrm{eV}$ was used for binding energy correction. A survey scan (1 sweep/200 ms dwell) was acquired between 1100 and $0 \mathrm{eV}$. Current region sweeps for N1s, O1s and C1s were obtained. CASA data processing software allowed smoothing, Shirley type background subtraction, peak fitting and quantification. Atomic percentages of each element were calculated from intensity ratios using Scofield sensitivity factors. ${ }^{23}$

Molasses- and sucrose-derived electrodes were prepared by spreading a paste $(\sim 3 \mathrm{mg})$ containing the carbon material, polytetrafluoroethylene (PTFE) binder and carbon black in the weight percent ratio of $85: 10: 5$ onto a graphite foil. The resultant electrodes were pressed at $5 \mathrm{MPa}$ and impregnated in $1 \mathrm{M} \mathrm{H}_{2} \mathrm{SO}_{4}$ electrolyte, or with $1 \mathrm{M} \mathrm{NaNO}_{3}$ for cyclic voltammetry measurements, during 48 hours.

Before impregnation, the electrical conductivity of these carbon pastes was measured by the four-probe method with a Keithley 237 source-measure unit. Disc-shaped carbon electrodes were used, having a diameter of $0.6 \mathrm{~cm}$ and a thickness determined as the average value $(\sim 0.3 \mathrm{~mm})$ of ten measurements using a Keyence LK-G32 non-contact profilometer. Electric contacts were ensured by copper wires glued with silver paint to the ends of the samples. The electric field was always maintained constant at $0.2 \mathrm{~V} \mathrm{~cm}^{-1}$, for which the currentvoltage characteristics always obeyed Ohm's law at room temperature. The electrical conductivity, $\sigma\left(\mathrm{S} \mathrm{cm}^{-1}\right)$, was then calculated by application of eqn (1):

$$
\sigma=\frac{1}{R} \frac{L_{0}}{S}
$$

where $R(\Omega)$ is the resistance obtained by dividing the voltage drop $V$ (volts) by the intensity $I$ (A) throughout the sample, $L_{0}$ (cm) is the average thickness of the sample and $S\left(\mathrm{~cm}^{2}\right)$ is the disc area.

Electrochemical performances of the carbon materials were studied by cyclic voltammetry (CV) and galvanostatic chargedischarge (GCD) techniques. Both kinds of measurements were carried out with a Biologic VMP3 electrochemical workstation in the potential window $0-0.7 \mathrm{~V}$.

Cyclic voltammetry (CV) tests were performed at different scan rates ranging from 0.5 to $100 \mathrm{mV} \mathrm{s}^{-1}$ in a three-electrode cell system, using a platinum gauze as the counter electrode and a saturated calomel electrode (SCE) as reference. The specific gravimetric capacitance $\left(C, \mathrm{~F} \mathrm{~g}^{-1}\right)$ was calculated from the CV curves according to eqn (2):

$$
C=\frac{\int I \Delta t}{s \Delta V m}
$$

where $I(\mathrm{~A})$ is the constant current, $s\left(\mathrm{~V} \mathrm{~s}^{-1}\right)$ is the scan rate, $\Delta V$ $(\mathrm{V})$ is the potential window and $m(\mathrm{~g})$ is the mass of active material.

GCD tests were carried out at current densities ranging from 0.1 to $5 \mathrm{~A} \mathrm{~g}^{-1}$ in a two-electrode cell system. Specific capacitance $\left(C, \mathrm{~F} \mathrm{~g}^{-1}\right)$, energy density $\left(E, \mathrm{~W} \mathrm{~h} \mathrm{~kg}{ }^{-1}\right)$ and power density $(P, \mathrm{~W}$ $\mathrm{kg}^{-1}$ ) were calculated from the GCD curves by applying eqn (3)(5), respectively:

$$
\begin{gathered}
C=(2 I) /[m(\mathrm{~d} V / \mathrm{d} t)] \\
E=C / 8(\Delta V-I R)^{2} \\
P=E / \Delta t
\end{gathered}
$$

where $I$ (A) represents the discharge current, $(\mathrm{d} V / \mathrm{d} t)\left(\mathrm{V} \mathrm{s}^{-1}\right)$ the slope of the discharge curve, $m(\mathrm{~g})$ the mass of active material, $\Delta V(\mathrm{~V})$ the potential difference within the discharge time $\Delta t(\mathrm{~s})$ and $I R$ the drop of voltage in the discharge process.

\section{Results and discussion}

Fig. 1a shows the $\mathrm{N}_{2}$ adsorption-desorption isotherms of the studied materials. Fig. 1b displays the PSDs calculated after applying the NLDFT model to both the $\mathrm{N}_{2}$ and the $\mathrm{CO}_{2}$ isotherms, and the inset shows the $\mathrm{CO}_{2}$ adsorption isotherms of the materials. Sucrose-derived carbon, SH-900, exhibited a type-I isotherm according to the IUPAC classification, typical of microporous materials. Its porosity was mainly composed of narrow micropores, of diameter $\sim 0.46 \mathrm{~nm}$, and of a low amount of wider micropores, of diameter centred on $1.55 \mathrm{~nm}$. Molasses-derived carbons presented type-IV isotherms, characteristic of mesoporous materials. The shape of their hysteresis cycle was not the same from one material to another: M-900 carbon, obtained from direct carbonisation, exhibited a very narrow hysteresis loop in the 0.5-1.0 range of relative pressure; $\mathrm{MH}-750$ and $\mathrm{MH}-900$ carbons, obtained through HTC followed by pyrolysis, displayed well-defined hysteresis loops in the 0.3-1.0 range of relative pressure with a jump in the desorption branch at the relative pressure of 0.5. These observations clearly indicate that the mesopore volume and the PSD in the mesopore range of the molassesderived samples depend on the synthesis method. Direct carbonisation produced less porous carbons, within the micro- and mesoporosity ranges, than HTC followed by carbonisation. 

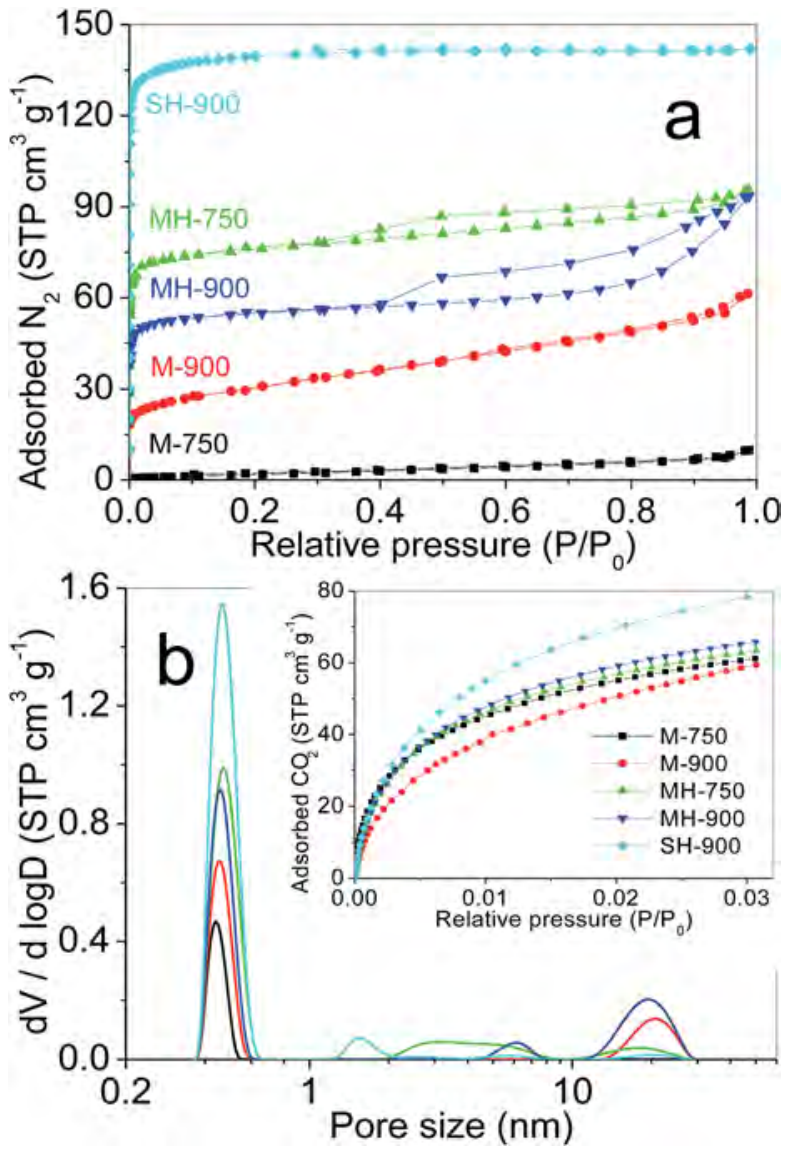

Fig. 1 (a) $\mathrm{N}_{2}$ adsorption-desorption isotherms at $-196{ }^{\circ} \mathrm{C}$; (b) corresponding pore size distributions and $\mathrm{CO}_{2}$ adsorption isotherms at $0{ }^{\circ} \mathrm{C}$ (inset) of the carbon materials.

Table 1 presents the textural parameters obtained from $\mathrm{N}_{2}$, $\mathrm{Kr}$ and $\mathrm{CO}_{2}$ adsorption isotherms. Although it is generally accepted that the DR method overestimates micropore volumes, ${ }^{24} V_{\mathrm{DR}-\mathrm{N}_{2}}$ and $V_{\mathrm{DR}-\mathrm{CO}_{2}}$ were reported here for comparison with previously reported data. $V_{\mathrm{DR}-\mathrm{CO}_{2}}$ was higher than both $V_{\mathrm{DR}-\mathrm{N}_{2}}$ and $V_{0.97, \mathrm{~N}_{2}}$ for all the samples, suggesting that the latter presented porosities mainly composed of narrow pores, not accessible to $\mathrm{N}_{2}$ at $-196{ }^{\circ} \mathrm{C}$.

Thus, $\mathrm{N}_{2}$ and the $\mathrm{CO}_{2}$ adsorption were both absolutely necessary to correctly evaluate the textural properties of these carbons.
We therefore applied the NLDFT model to the $\mathrm{N}_{2}$ and the $\mathrm{CO}_{2}$ adsorption data to obtain the micropore, $V_{\mu-\mathrm{NLDFT}}$, and the total pore volume, $V_{\mathrm{T} \text {-NLDFT }}$. Both $V_{\mu \text {-NLDFT }}$ and $V_{\text {T-NLDFT }}$ values were indeed higher when calculated from $\mathrm{CO}_{2}$ isotherms than from $\mathrm{N}_{2}$ isotherms, thereby confirming the need of using both gases to characterise adequately these samples. The $A_{\mathrm{BET}}$ values showed the same trend as those of $S_{\mathrm{NLDFT}}$ but, as expected, the former were lower than the latter because the BET method underestimates the surface area when materials are essentially ultramicroporous. ${ }^{24}$

Molasses and sugar hydrochars, $\mathrm{MH}$ and $\mathrm{SH}$, had very low $A_{\text {BET }}$ determined by krypton adsorption at $-196^{\circ} \mathrm{C}, \sim 0.4$ and $\sim 2$ $\mathrm{m}^{2} \mathrm{~g}^{-1}$, respectively, which can be attributed to the external surface area of the materials. Porosity development took place during subsequent carbonisation, due to the evolution of volatiles, and $S_{\text {NLDFT }}$ values of 429 and $836 \mathrm{~m}^{2} \mathrm{~g}^{-1}$ ( $A_{\mathrm{BET}}$ of 214 and $562 \mathrm{~m}^{2} \mathrm{~g}^{-1}$ ) were attained for MH-900 and SH-900, respectively. As seen in Table 1, higher surface areas were obtained when a preliminary HTC step was used in the preparation of the samples. This fact could be due to the partial dissolution of inorganic impurities in hot water when working in hydrothermal conditions. The pyrolysis temperature proved to have a significant effect on the molasses-derived carbons obtained either by HTC and subsequent carbonisation or by direct carbonisation. In the case of HTC + pyrolysis, $S_{\text {NLDFT }}$ decreased (from 523 to $429 \mathrm{~m}^{2} \mathrm{~g}^{-1}$ ) when increasing the carbonisation temperature from 750 to $900{ }^{\circ} \mathrm{C}$, which is mainly due to pore widening without micropore generation. In the case of direct carbonisation of molasses, $S_{\mathrm{NLDFT}}$ of $178 \mathrm{~m}^{2} \mathrm{~g}^{-1}$ at $750{ }^{\circ} \mathrm{C}$ and of $302 \mathrm{~m}^{2} \mathrm{~g}^{-1}$ at $900{ }^{\circ} \mathrm{C}$ were measured, due to micropore generation.

According to the supplier, the raw molasses contained 30.3 $\mathrm{wt} \%$ of sucrose, $18.9 \mathrm{wt} \%$ of reducing sugars and $18.9 \mathrm{wt} \%$ of other carbohydrates, in good agreement with the organic matter fraction (68.2 wt\%) determined in this study. The high ash content $(\sim 9.6 \mathrm{wt} \%)$ is due to the presence of inorganic salts and metals, mainly coming from the chemical fertilisers used on farmlands. These inorganic compounds were retained in some extent in the material after carbonisation, as corroborated by the XRD profile and the SEM-EDS analysis of M-750 shown in Fig. 2a and c. The XRD profile (Fig. 2a) evidenced the presence of $\mathrm{KCl}$ as the main impurity, as well as the SEM-EDS results, in which potassium was found at a concentration of $2.5 \mathrm{wt} \%(62.5$

Table 1 Textural parameters calculated from $\mathrm{N}_{2}$ and $\mathrm{Kr}$ adsorption at $-196{ }^{\circ} \mathrm{C}$ and from $\mathrm{CO}_{2}$ adsorption at $0{ }^{\circ} \mathrm{C}$

\begin{tabular}{|c|c|c|c|c|c|c|c|c|}
\hline Sample & $\begin{array}{l}A_{\mathrm{BET}} \\
\left(\mathrm{m}^{2} \mathrm{~g}^{-1}\right)\end{array}$ & $\begin{array}{l}S_{\mathrm{NLDFT}} \\
\left(\mathrm{m}^{2} \mathrm{~g}^{-1}\right)\end{array}$ & $\begin{array}{l}V_{0.97, \mathrm{~N}_{2}} \\
\left(\mathrm{~cm}^{3} \mathrm{~g}^{-1}\right)\end{array}$ & $\begin{array}{l}V_{\mu-\mathrm{DR}, \mathrm{N}_{2}} \\
\left(\mathrm{~cm}^{3} \mathrm{~g}^{-1}\right)\end{array}$ & $\begin{array}{l}V_{\mu-\mathrm{DR}, \mathrm{CO}_{2}} \\
\left(\mathrm{~cm}^{3} \mathrm{~g}^{-1-1}\right)\end{array}$ & $\begin{array}{l}V_{\mathrm{T}-\mathrm{NLDFT}} \\
\left(\mathrm{cm}^{3} \mathrm{~g}^{-1}\right)\end{array}$ & $\begin{array}{l}V_{\mu-\mathrm{NLDFT}} \\
\left(\mathrm{cm}^{3} \mathrm{~g}^{-1}\right)\end{array}$ & $\begin{array}{l}V_{\text {meso }} \\
\left(\mathrm{cm}^{3} \mathrm{~g}^{-1}\right)\end{array}$ \\
\hline M-750 & 8 & 178 & 0.02 & 0.01 & 0.16 & 0.04 & 0.04 & $0.00(0 \%)$ \\
\hline MH & $0.4^{a}$ & - & - & - & - & - & - & - \\
\hline MH-750 & 232 & 523 & 0.10 & 0.12 & 0.20 & 0.15 & 0.12 & $0.03(20 \%)$ \\
\hline MH-900 & 214 & 429 & 0.11 & 0.07 & 0.21 & 0.15 & 0.10 & $0.05(33 \%)$ \\
\hline
\end{tabular}

${ }^{a} S_{\mathrm{BET}}$ determined by $\mathrm{Kr}$ adsorption at $-196^{\circ} \mathrm{C}$. 
$\mathrm{wt} \%$ lower than in the raw material). The calcium content was $\sim 1.3 \mathrm{wt} \%$, and the remaining elements were found at concentrations $<1 \mathrm{wt} \%$.

In order to determine the solubility of the inorganic impurities, M-750 carbon was washed several times with distilled water and subsequently dried under vacuum $\left(80^{\circ} \mathrm{C}, 12 \mathrm{~h}\right)$. The corresponding XRD profile and SEM-EDS analysis displayed in Fig. $2 b$ and $d$, respectively, revealed that $\mathrm{K}, \mathrm{Na}$ and Fe were removed, indicating that they were part of the soluble compounds. The presence of $\mathrm{Ca}(1.3 \mathrm{wt} \%)$ and $\mathrm{Mg}(0.6 \mathrm{wt} \%)$ indicates that they were in the form of insoluble compounds. No significant changes in the porosity of the material were observed after the washing step.

The TG/DTG curves of the raw molasses are displayed in Fig. 3. The TG curve of the raw molasses presented four main weight loss steps associated to endothermic peaks in the DTG curve (at 118, 207, 690 and $\sim 900{ }^{\circ} \mathrm{C}$ ). The first mass loss occurring between 30 and $160{ }^{\circ} \mathrm{C}(\sim 22 \%)$ can be assigned to moisture release. The second stage between 160 and $283{ }^{\circ} \mathrm{C}$ $(33.2 \%)$ may be associated to the pyrolysis of both sugar and non-sugar organic constituents and breakdown of

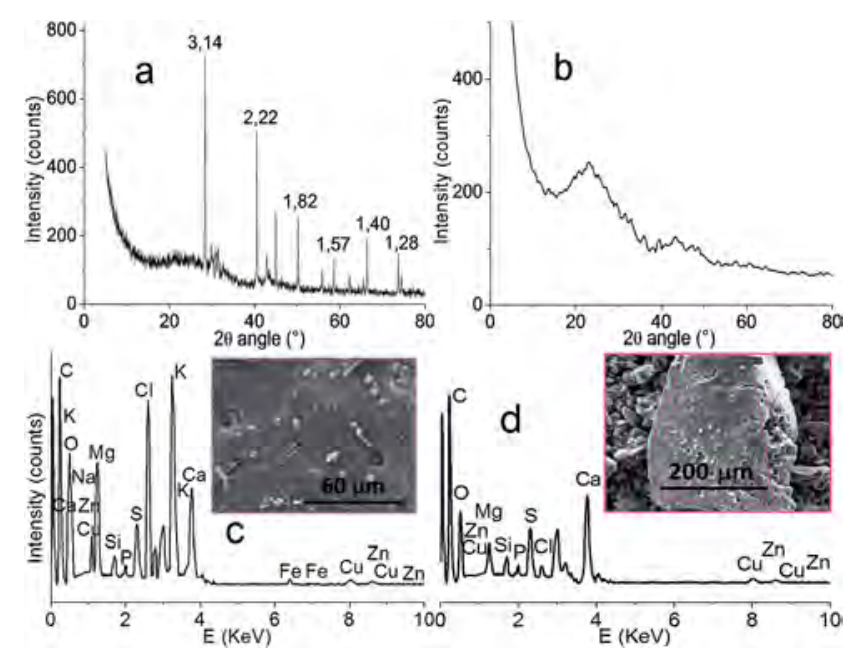

Fig. 2 XRD patterns of M-750 samples: (a) before, and (b) after having being washed with water; (c) and (d) corresponding SEM images and EDS results before and after $M-750$ was washed with water, respectively.

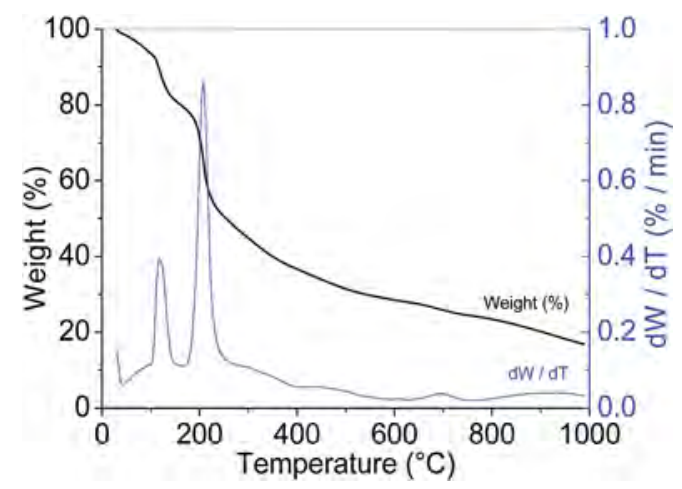

Fig. 3 TG and DTG curves of the raw molasses in inert atmosphere. polysaccharide molecules, water and CO molecules being the main resultant gaseous by-products. ${ }^{25}$ The breakdown of polysaccharide molecules is probably produced until $\sim 600{ }^{\circ} \mathrm{C}(18.1$ wt $\%$ mass loss), as indicated by the continuous weight loss observed in the TG curve, in agreement with a previous study on sugarcane molasses. ${ }^{26}$ In addition, this latter work indicated that the weight loss was negligible from 500 to $700{ }^{\circ} \mathrm{C}$ and that no weight loss was observed up to $900{ }^{\circ} \mathrm{C}^{26}$ In contrast, our TG/ DTG curves presented two steps between $\sim 600$ and $758{ }^{\circ} \mathrm{C}$ and above $758^{\circ} \mathrm{C}$ with no negligible weight loss values of 3.6 and 7.4 wt $\%$, respectively. Such unexpected stages appearing above 600 ${ }^{\circ} \mathrm{C}$ will be explained in detail hereinafter.

The bulk chemical composition of the studied materials, determined by elemental analysis and TPD, as well as the total yields of synthesis and the electrical conductivities are gathered in Table 2. Bulk oxygen concentration was only estimated from TPD experiments, since the high ash content of the samples present in molasses led to erroneous results by elemental analysis. Nevertheless, the as-determined oxygen concentration was only estimation, because nitrogen and sulphur oxides originating from the decomposition of $\mathrm{N}$ and $\mathrm{S}$ moieties present in the samples could not be determined by TPD. The composition of commercial sucrose is $42 \mathrm{wt} \% \mathrm{C}, 6.5 \mathrm{wt} \% \mathrm{H}$ and 51.5 wt $\%$ O. After HTC, the carbon content increased from 42 to 65.6 wt $\%$ (56\% increase) and the hydrogen content decreased accordingly from 6.5 to $4.4 \mathrm{wt} \%$ (58.4\% decrease), thereby indicating the increase of the aromatic character of the material. Subsequent carbonisation at $900{ }^{\circ} \mathrm{C}$ further increased the carbon content from 65.6 to $93 \mathrm{wt} \%$ (i.e., $+41.7 \%$ ) and decreased the hydrogen concentration from 4.4 to $0.1 \mathrm{wt} \%$ (i.e., $-98.9 \%$ ). When comparing the carbon enrichment achieved by both processes, the effectiveness of HTC, as a low-temperature pretreatment followed by carbonisation, for biomass-based materials is obvious.

Direct carbonisation of molasses is indeed a violent process producing sample foaming and a partial loss of material. For this reason, carbon yields for M-750 and M-900 were not reported here. As expected, increasing the carbonisation temperature reduced the total yield, regardless of the synthesis method used.

Table 2 Data of bulk chemical composition from elemental analysis and TPD experiments, and total yield $(\eta)$ of the materials under study. Electrical conductivity $(\sigma)$ of a paste based on the same carbon materials

\begin{tabular}{|c|c|c|c|c|c|c|c|c|}
\hline \multirow[b]{2}{*}{ Sample } & \multicolumn{4}{|c|}{$\begin{array}{l}\text { Elemental analysis } \\
(\mathrm{wt} \%)\end{array}$} & \multicolumn{2}{|c|}{$\begin{array}{l}\text { TPD } \\
\left(\mathrm{mmol} \mathrm{g}^{-1}\right) \\
\end{array}$} & \multirow[b]{2}{*}{$\eta(\%)$} & \multirow[b]{2}{*}{$\sigma\left(\mathrm{S} \mathrm{cm}^{-1}\right)$} \\
\hline & $\mathrm{C}$ & $\mathrm{H}$ & $\mathrm{N}$ & S & $\mathrm{CO}$ & $\mathrm{CO}_{2}$ & & \\
\hline M-750 & 60.0 & 1.4 & 0.9 & 1.9 & 2.68 & 3.30 & - & 0.015 \\
\hline M-900 & 61.7 & 1.1 & 0.9 & 2.1 & 2.83 & 3.06 & - & 2.006 \\
\hline MH & 64.8 & 5.1 & 1.2 & 0.3 & 2.54 & 5.12 & 35.6 & - \\
\hline MH-750 & 84.9 & 1.6 & 1.1 & 0.4 & 1.96 & 3.35 & 19.3 & 0.054 \\
\hline MH-900 & 86.9 & 0.8 & 1.0 & 0.5 & 1.89 & 2.48 & 17.9 & 0.356 \\
\hline $\mathrm{SH}$ & 65.6 & 4.4 & 0.0 & 0.0 & 1.86 & 6.51 & 41.1 & - \\
\hline SH-900 & 93.0 & 0.1 & 0.1 & 0.0 & 1.37 & 2.98 & 21.1 & 13.800 \\
\hline
\end{tabular}


As for the chemical composition, $\mathrm{MH}-750$ and $\mathrm{MH}-900$ exhibited lower oxygen and sulphur contents, as well as lower ash content $(\sim 10 \mathrm{wt} \%)$ in their bulk than the samples directly carbonised. This feature may be due to the HTC conditions, aqueous medium and autogenous pressure, favouring the removal of soluble by-products and inorganic compounds from molasses. The carbon content of M-750 and M-900 was very low, mainly due to the high ash content of these samples ( $\sim 23 \mathrm{wt} \%)$. The bulk oxygen content of the molasses-derived samples was very high, especially for M-750 and M-900, as deduced from the $\mathrm{CO}$ and $\mathrm{CO}_{2}$ concentrations measured in the TPD experiments. On the contrary, sugar-derived carbon, SH-900, displayed the lowest $\mathrm{CO}$ and $\mathrm{CO}_{2}$ concentrations $(\sim 3 \mathrm{wt} \%)$, in agreement with the lower oxygen concentration of sucrose.

It is generally assumed that oxygen functional groups of carbons desorb into $\mathrm{CO}$ and/or $\mathrm{CO}_{2}$ gases during TPD experiments. As shown in Table 2, the $\mathrm{CO}_{2}$ concentration is slightly higher than the CO concentration for all the samples. On one hand, oxygen functionalities possessing a basic character such as quinones, semiquinones, hydroquinones, ethers, phenols, carbonyls and chromenes decompose into $\mathrm{CO}$ at different temperatures. On the other hand, acidic oxygen functionalities such as carboxylic acids, lactones and lactols desorb as $\mathrm{CO}_{2}$. Carboxylic anhydrides decompose in equal amounts of $\mathrm{CO}$ and $\mathrm{CO}_{2} \cdot{ }^{27}$ From the TPD results it appears that the concentration of acidic groups in the bulk of the carbons is higher than that of basic groups. MH-750 presented the highest concentration of acidic groups while M-900 exhibited the highest content of basic groups. Molasses samples presented $\sim 1 \mathrm{wt} \% \mathrm{~N}$, slightly higher in MH-750 and MH-900 than in M-750 and M-900, respectively. This supports the fact that HTC favours nitrogen retention in the materials bulk. It is remarkable that the bulk sulphur content in the molasses-derived samples carbonised at $900{ }^{\circ} \mathrm{C}$ was higher than in those carbonised at $750{ }^{\circ} \mathrm{C}$, independently of the synthesis method used. This fact was also observed at the surface of the respective samples, as displayed in Table $\mathrm{S}-1$ (ESI section $\dagger$ ).

XPS data also evidenced the presence of several ions and metals in the material surface, namely $\mathrm{K}, \mathrm{Ca}, \mathrm{Na}, \mathrm{Cl}, \mathrm{Cu}, \mathrm{Zn}, \mathrm{Mg}$ and Si. Such inorganics were mainly found in M-750 and M-900 carbons, confirming that the HTC process induced the leaching of some inorganics from molasses. All the molasses-derived carbons also contained $\mathrm{Ca}$ in the form of $\mathrm{CaO}$ and $\mathrm{CaSO}_{4},{ }^{28,29}$ as shown in Table $\mathrm{S}-1 \dagger$ and in the XPS profiles of Fig. S-1 (ESI section $\dagger$ ). The presence of these insoluble calcium salts supports XRD and SEM-EDS results previously discussed in which calcium remaining after washing molasses-based carbons was evidenced.

The S2p high-resolution spectra and the corresponding data of binding energy and relative area contributions to the $\mathrm{S} 2 \mathrm{p}$ peak for the studied carbons are displayed in Table S-2 and Fig. S-3 (ESI section $\dagger$ ), respectively.

Deconvolution of the S2p high-resolution spectra gave rise to two peaks assigned to oxidised sulphur $\left(\mathrm{SO}_{4}{ }^{2-}\right)$ and to sulphide $\left(\mathrm{S}^{2-}\right)$, respectively, as displayed in Table $\mathrm{S}-2 . \dagger$ The sulphate concentration was higher in the directly carbonised samples than in those obtained through HTC + pyrolysis. When the carbonisation temperature increased from 750 to $900{ }^{\circ} \mathrm{C}$, the sulphate content increased along with the decrease of sulphide content (released from the carbon above $500{ }^{\circ} \mathrm{C}$ ). ${ }^{30}$ Moreover, the samples carbonised at $900{ }^{\circ} \mathrm{C}$ presented higher oxygen and lower carbon contents, which is quite unusual taking into account that increasingly high carbonisation temperatures are usually related to higher graphitisation degrees and, consequently, to higher carbon/heteroatom ratios. ${ }^{31}$ This finding can, however, be explained by the oxidising character of sulphates at high temperature, according to the following reactions: ${ }^{32-34}$

$$
\begin{gathered}
\mathrm{CaSO}_{4}(\mathrm{~s})+2 \mathrm{C}(\mathrm{s}) \rightarrow \mathrm{CaS}(\mathrm{s})+2 \mathrm{CO}_{2}(\mathrm{~g}) \\
\mathrm{CaS}(\mathrm{s})+3 \mathrm{CaSO}_{4}(\mathrm{~s}) \rightarrow \mathrm{CaO}(\mathrm{s})+2 \mathrm{SO}_{2}(\mathrm{~g}) \\
3 \mathrm{CaS}(\mathrm{s})+\mathrm{CaSO}_{4}(\mathrm{~s}) \rightarrow 4 \mathrm{CaO}(\mathrm{s})+2 \mathrm{~S}_{2}(\mathrm{~g})
\end{gathered}
$$

Typically, reaction (6) takes place between 750 and $1080{ }^{\circ} \mathrm{C}$ whereas reactions (7) and (8) occur in the same extent between 900 and $1000{ }^{\circ} \mathrm{C}$; the generated $\mathrm{SO}_{2}$ and $\mathrm{S}_{2}$ react with carbon and give rise to sulphur bound to carbon.

These transformations may explain some of the textural and chemical events observed above $750{ }^{\circ} \mathrm{C}$ : (i) the better porous texture development of the samples carbonised at $900{ }^{\circ} \mathrm{C}$ with respect to those carbonised at $750{ }^{\circ} \mathrm{C}$, especially in the directly carbonised molasses, due to the activating effect of $\mathrm{CO}_{2}$. It is worth recalling that, in molasses-derived samples obtained through HTC, a widening effect of pre-existing micropores was observed, producing a slight decrease of $S_{\mathrm{BET}}$; (ii) the high oxygen and low carbon contents of the samples carbonised at $900{ }^{\circ} \mathrm{C}$, owing to the oxidation of the carbon matrix by sulphates; the highly oxidised areas of the carbon matrices might finally produce $\mathrm{CO}_{2}$, contributing to the porous texture development and to the removal of carbon atoms from the matrix; (iii) the fixation of sulphur and other elements, such as $\mathrm{Ca}$ or $\mathrm{Mg}$, in the samples carbonised at $900{ }^{\circ} \mathrm{C}$ : the concentration of these elements increased because of the change in the carbon/heteroelements ratio; (iv) the weight loss occurring above $600{ }^{\circ} \mathrm{C}$ observed in TG/DTG curves, assigned to the loss of gaseous by-products generated as a consequence of the chemical transformations.

Fig. S-3-S-5† display the C1s, N1s and O1s high-resolution spectra of the studied materials, respectively, and Table 3 collects the corresponding quantification data. ${ }^{35-37}$ No nitrogen was detected at the surface of M-750, M-900 and SH-900. Nitrogen of sugarcane molasses was transformed into pyridinic and amino groups during HTC; after subsequent carbonisation, the latter were mainly converted into pyridinic, pyrrolic and quaternary nitrogen, and into nitrogen oxides in a minor extent. Regarding the O1s high-resolution spectra, it is noteworthy that the relative area of OIII peak is very high in the samples carbonised at $900{ }^{\circ} \mathrm{C}$ and in those obtained through HTC + pyrolysis. This finding suggests the presence of highly oxidised functional groups in the carbons (carboxylic acids) and supports the oxidation of the carbon matrix by sulphates above $750{ }^{\circ} \mathrm{C}$. Taking into account the surface oxygen content and the relative areas of each peak, M-750 exhibited the highest 
concentration of quinones and carbonyls (OI); M-900 possessed the highest amount of the rest of oxygen functionalities (OII and OIII) and a surface concentration of quinones and carbonyls slightly lower than that of M-750. Among the samples obtained through HTC, MH-750 presented the highest concentrations of quinone-type and carbonyl groups (OI) and of the oxygen functionalities assigned to OII peak (ethers, esters, phenols and anhydrides). ${ }^{35-37}$

The morphology of carbon particles was investigated by SEM. Fig. S-6† displays SEM images of carbons derived from molasses and sucrose hydrochars as well as from directly carbonised molasses. SEM photograph of Fig. S-6a† shows that MH-900 was composed of heterogeneous carbon particles exhibiting uneven shapes with an average size $\sim 4 \mu \mathrm{m}$. Particle heterogeneity may be due to the complex chemical composition and to the high ash content of the molasses used as precursor. SEM image of Fig. S-6b† shows that SH-900 comprised interconnected and heterogeneous carbon spheres with an average diameter of $\sim 1-2 \mu \mathrm{m}$, whereas some bigger spheres of diameter $\sim 5 \mu \mathrm{m}$ were also observed. It has indeed been reported that the kinetics of sucrose reactions under HTC conditions are very high, so that a high number of seeds are formed and smaller spheres are finally obtained. ${ }^{38}$ SEM image of M-900 (Fig. S-6c $\dagger$ ) illustrates that directly carbonized molasses are composed of heterogeneous particles as for the carbons obtained from molasses hydrochars, but their sizes ranged from a few microns to more than $200 \mu \mathrm{m}$.

The electrical conductivities of the molasses-derived carbons were quite low compared to that of $\mathrm{SH}-900$, obtained from sucrose, probably due to the much lower ash and oxygen contents of the latter. The materials carbonised at $750{ }^{\circ} \mathrm{C}, \mathrm{M}-750$ and $\mathrm{MH}-750$, were the least conductive materials according to their electrical conductivity values of $0.035 \pm 0.015 \mathrm{~S} \mathrm{~cm}^{-1}$. Increasing the carbonisation temperature from 750 to $900{ }^{\circ} \mathrm{C}$ produced an increase of electrical conductivity by 7 times for the molasses samples derived from HTC, and by 100 times for the directly carbonised samples. Differences of electrical conductivity among the samples can be explained by three main factors: (i) surface chemistry of the materials, in particular the different concentration and types of oxygen and sulphur groups; ${ }^{39}$ (ii) order at atomic level arising from the increase of carbonisation temperatures; ${ }^{\mathbf{4 0}}$ (iii) size of the particles: smaller sizes promoting intra-particle resistances, thus decreasing the electrical conductivity of the material. After removal of $\mathrm{KCl}$, which is a dielectric salt, the conductivity of M-750 for example increased from 0.015 to $0.077 \mathrm{~S} \mathrm{~cm}^{-1}$.

The electrochemical behaviour of the carbons was studied by cyclic voltammetry in $1 \mathrm{M} \mathrm{H}_{2} \mathrm{SO}_{4}$ electrolyte. Fig. 4a shows the cyclic voltammograms of the studied carbons in the aforementioned electrolyte within the potential window from 0 to 0.7 $\mathrm{V}$ (vs. SCE) at $0.5 \mathrm{mV} \mathrm{s}^{-1}$ scan rate. All samples exhibited quasirectangular $\mathrm{CV}$ curves and redox peaks at low sweep rates (Fig. 4a). Deviations from the rectangular shape of the CV curves are explained by faradaic reactions of oxygen and/or nitrogen functional groups, which participate to the total capacitance through pseudocapacitance contribution. No correlation was found between the carbonisation temperature and the anodic 



Fig. 4 Electrochemistry results obtained from CV experiments carried out with a three-electrode cell: (a) cyclic voltammograms of all carbons in the potential range of $0-0.7 \mathrm{~V}$ at the scan rate of $0.5 \mathrm{mV} \mathrm{s}^{-1}$; (b) specific capacitance as a function of scan rate; (c) retention of specific capacitance as a function of scan rate; (d) cycling stability of raw and washed $M-750$ samples at the scan rates of 0.5 and $10 \mathrm{mV} \mathrm{s}^{-1}$.

and cathodic current densities obtained, since the samples carbonised at $900{ }^{\circ} \mathrm{C}$ did not exhibit higher current density values. However, a correlation was found between the $\mathrm{CV}$ curves and the method by which the carbons were prepared: whereas the samples directly carbonised (M-750 and M-900) exhibited high current densities and broad redox peaks in the potential range of $0.15-0.5 \mathrm{~V}$ (due to oxygen groups), the materials prepared by HTC (MH-750, MH-900 and SH-900) showed low current density values and small peaks between 0.3 and $0.5 \mathrm{~V}$ (due to oxygen and nitrogen groups).

Fig. $4 \mathrm{~b}$ displays the specific capacitance evolution for the different samples as a function of scan rate. The samples prepared by direct carbonisation yielded higher specific capacitance values in the studied sweep rate interval than the HTCderived ones, whose specific capacitances were very similar to each other. Thus, M-750 and M-900 presented specific capacitances of 153 and $131 \mathrm{~F} \mathrm{~g}^{-1}$ at $0.5 \mathrm{mV} \mathrm{s}^{-1}$. The CV curves of M900 and MH-900 exhibited a quasi-rectangular shape up to 20 $\mathrm{mV} \mathrm{s}^{-1}$ (Fig. S-7 in ESI section $\uparrow$ shows MH-900 as representative sample), and these carbons yielded the higher values of capacitance retention as a function of scan rate, $\sim 40 \%$ at $100 \mathrm{mV} \mathrm{s}^{-1}$ (Fig. 4c) due to their higher mesopore volumes in comparison with the other carbons. The CV curves of M-750 and SH-900 maintained their quasi-rectangular shapes up to a scan rate of $10 \mathrm{mV} \mathrm{s}^{-1}$ (Fig. S-7 $\dagger$ displays M-750 as representative sample), and the capacitance retention only reached 21 and $26 \%$ at 100 $\mathrm{mV} \mathrm{s}^{-1}$, respectively. This finding is explained by their porous texture, mainly composed of ultramicropores (diameter $\sim 0.5$ $\mathrm{nm}$ ), hardly accessible to the hydrated ions of the electrolyte. ${ }^{41}$ These small pores are indeed well-known to increase the inner resistance of the system and thus hinder electrolyte ions transport at high scan rates.

$\mathrm{CV}$ tests were also carried out in an EDLC-only system, $1 \mathrm{M}$ $\mathrm{NaNO}_{3}$ electrolyte, in order to determine the respective contributions of the EDL and of the faradaic reactions to the total capacitance. The resultant $\mathrm{CV}$ curves at $0.5 \mathrm{mV} \mathrm{s}^{-1}$ and capacitance results at different scan rates for two representative samples, M-750 and MH-750, are shown in Fig. S-8. $\dagger$ When comparing the $\mathrm{CV}$ curves obtained in the two electrolytes, the existence of broad redox peaks in $\mathrm{H}_{2} \mathrm{SO}_{4}$ is evidenced for $\mathrm{M}-750$, especially between 0 and $0.5 \mathrm{~V}$ (Fig. S-8a $\uparrow$ ). The capacitance in $\mathrm{NaNO}_{3}$ is $31.4 \%$ lower than that obtained in $\mathrm{H}_{2} \mathrm{SO}_{4}$ and this difference could be related to the pseudocapacitance contribution of the system (Fig. S-8c†). On the contrary, such difference is negligible for $\mathrm{MH}-750$, indicating that the capacitance is mainly controlled by an EDL mechanism (Fig. S-8b and $d \dagger$ ).

The effect of $\mathrm{KCl}$ on the electrochemical performances of the carbons was studied by CV. Fig. $4 \mathrm{~d}$ displays the evolution of specific capacitance, measured at scan rates of 0.5 and $10 \mathrm{mV}$ $\mathrm{s}^{-1}$, as a function of the number of cycles for raw and washed $\mathrm{M}$ 750 samples. The washed samples did not contain $\mathrm{KCl}$ and yielded specific capacitance values 7 and $11 \%$ higher than the corresponding values for $\mathrm{M}-750$ at 0.5 and $10 \mathrm{mV} \mathrm{s}^{-1}$, respectively.

Since the porous texture was almost unaffected after $\mathrm{KCl}$ removal, as observed above, the enhanced CV performance might be related to the increase of electrical conductivity. The cycling stability of both carbons was similar and the specific capacitance values remained almost constant until 1500 cycles at both 0.5 and $10 \mathrm{mV} \mathrm{s}^{-1}$ scan rates.

To further study the electrochemical performances of the present materials, GCD tests were carried out in a two-electrode cell, and the results are shown in Fig. 5. The charge-discharge curves obtained at $0.5 \mathrm{~A} \mathrm{~g}^{-1}$ for the molasses-based carbons (Fig. 5a) presented a slightly asymmetric shape, non-linear voltage profiles and increasing $I R$ drops at increasing current densities, suggesting the existence of faradaic processes associated to nitrogen and/or oxygen moieties. These features are explained by the existence of high ion-transport resistances and low electrical conductivities. On the contrary, the GCD curves of SH-900 possessed symmetrical and quasi-triangular shape, small IR drop and short charge-discharge times, suggesting a more ideal capacitive behaviour.

As shown in Fig. 5b, M-750 yielded the highest value of gravimetric capacitance at low current density, $\sim 32 \mathrm{~F} \mathrm{~g}^{-1}$. According to the approach proposed by Centeno and Stoeckli ${ }^{42}$ and using the $A_{\mathrm{BET}}$ value in the equation, the pseudocapacitance contribution to the total capacitance was $\sim 97.1 \%$. M-900 presented a gravimetric capacitance of $\sim 27 \mathrm{~F} \mathrm{~g}^{-1}$ at low current density, and the pseudocapacitance contribution was lower, $56.6 \%$. Interestingly, $\mathrm{MH}-750$ and $\mathrm{MH}-900$ presented gravimetric capacitances of $\sim 3$ and $8 \mathrm{~F} \mathrm{~g}^{-1}$ at low current density despite possessing $A_{\mathrm{BET}}$ values of 232 and $214 \mathrm{~m}^{2} \mathrm{~g}^{-1}$, respectively. Both samples exhibited no pseudocapacitance contribution; this is quite surprising taking into account that the surface oxygen content of both materials was 7.5 at\%, and could be related to a low accessibility of electrolyte ions to the surface functionalities. SH-900, which presented an $A_{\mathrm{BET}}$ as high as 562 $\mathrm{m}^{2} \mathrm{~g}^{-1}$, yielded the lowest specific capacitance at low current density, $2 \mathrm{~F} \mathrm{~g} \mathrm{~g}^{-1}$, with no pseudocapacitance contribution. However, considering for example the $S_{\mathrm{NLDFT}}$ value of M-750, 

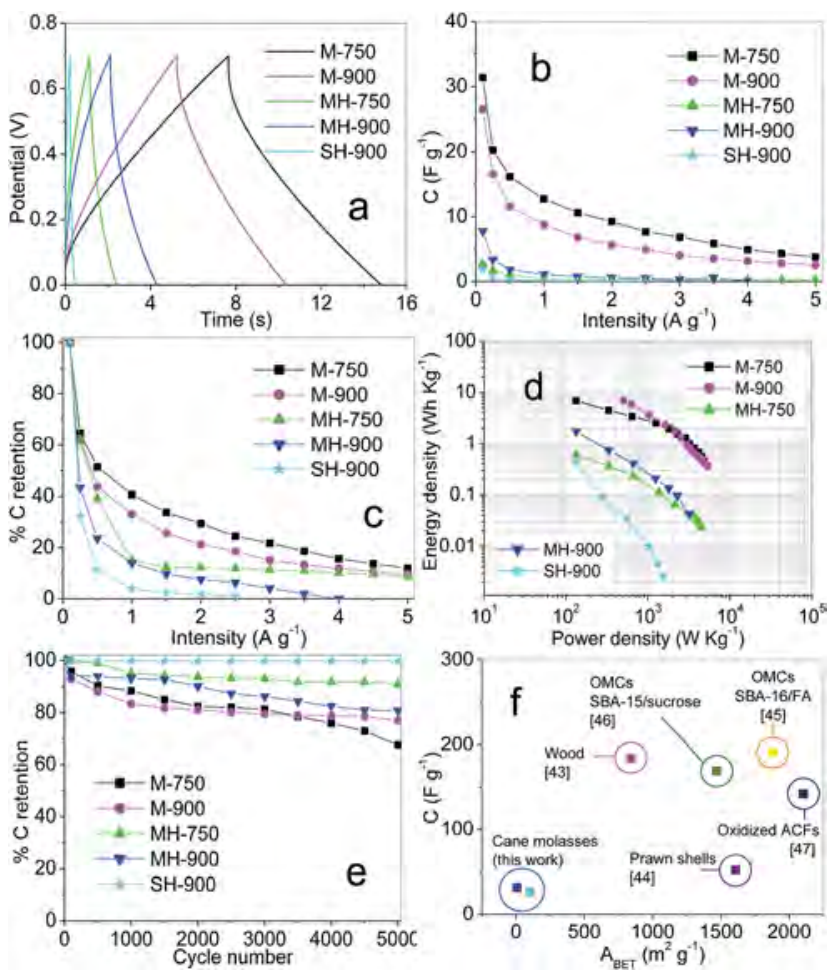

Fig. 5 Results obtained from GCD experiments carried out in a twoelectrode cell: (a) GCD curves at $0.5 \mathrm{~A} \mathrm{~g}^{-1}$ current density; (b) evolution of specific capacitance as a function of applied current; (c) percentage of capacitance retention versus applied current; (d) Ragone plot; (e) cycling stability of the carbon electrodes at $0.5 \mathrm{~A} \mathrm{~g}^{-1}$ until 5000 cycles; (f) specific capacitances versus $S_{B E T}$ for $M-750$ and $M-900$ samples studied in this work, and for other materials found in the literature: OMCs = ordered mesoporous carbons; ACFs = activated carbon nanofibres.

the pseudocapacitance reached only $35.2 \%$, which is similar to $31.4 \%$ calculated from CV tests in $\mathrm{H}_{2} \mathrm{SO}_{4}$ and $\mathrm{NaNO}_{3}$ electrolytes. This could indicate that $A_{\mathrm{BET}}$ really underestimates the surface area accessible to the electrolyte in this type of materials exhibiting narrow porosities, while $S_{\mathrm{NLDFT}}$ leads to a better estimation of the pseudocapacitance contribution.

Increasing the current density strongly affected the specific capacitances of the materials (Fig. 5c); M-750, M-900 and $\mathrm{MH}-$ 750 presented low capacitance retention at $5 \mathrm{~A} \mathrm{~g}^{-1}, 10-12 \%$, in agreement with the pronounced pseudocapacitive behaviour of both materials.

The Ragone plot displayed in Fig. 5d further confirmed these results. M-750 and M-900 exhibited the highest energy density at $0.1 \mathrm{~A} \mathrm{~g}^{-1}$ of $\sim 6.9 \mathrm{~W} \mathrm{~h} \mathrm{~kg}^{-1}$ under power outputs of 132 and $500 \mathrm{~W} \mathrm{~kg}^{-1}$, respectively. On the contrary, SH-900 yielded poor energy and power densities of $0.42 \mathrm{~W} \mathrm{~h} \mathrm{~kg}^{-1}$ and $132 \mathrm{~W} \mathrm{~kg}^{-1}$, respectively, which sharply decreased with the current density. Few works studying sugarcane molasses-based carbons as electrode materials for SCs can be found in literature. Capacitance values of $\sim 172 \mathrm{~F} \mathrm{~g}^{-1}$ at $1 \mathrm{~A} \mathrm{~g}^{-1}$ current density were reported in a former work, in which electrospun carbon microfibres obtained from cane molasses and 1.5 M tetraethyl ammonium tetrafluoroborate in acetonitrile electrolyte were used. ${ }^{26}$ M-750 and M-900 carbons exhibited specific capacitance values of $\sim 13$ and $9 \mathrm{~F} \mathrm{~g}^{-1}$, respectively, at the same current density, but their surface areas were considerably lower (8 and $102 \mathrm{~m}^{2} \mathrm{~g}^{-1}$, respectively) than those of the electrospun carbon fibres $\left(580 \mathrm{~m}^{2} \mathrm{~g}^{-1}\right)$ and different electrolytes were also used.

The stability of the carbon-based supercapacitors was studied by long-term charge-discharge cycling at the current density of $0.5 \mathrm{~A} \mathrm{~g}^{-1}$ (Fig. 5e). More than $67 \%$ specific capacitance was retained over 5000 cycles in the studied carbon-based supercapacitors. The cycling performances showed an inverse relationship with the magnitude of the pseudocapacitance contribution: M-750 and M-900 exhibited the lowest cycling performances of 67.6 and $77.0 \%$, respectively, $\mathrm{MH}-900$ had an intermediate cycling performance of $80.8 \%$, and $\mathrm{MH}-750$ and SH-900 yielded the highest performances of 90.9 and $99.7 \%$, respectively.

Fig. $5 \mathrm{f}$ shows some data of specific capacitances obtained in a two-electrode cell with $1 \mathrm{M} \mathrm{H}_{2} \mathrm{SO}_{4}$ electrolyte and $A_{\mathrm{BET}}$ values of previous works dealing with carbon-based supercapacitors. M-750 and M-900 studied in this work exhibited much lower $A_{\mathrm{BET}}$ values than all other carbon materials, such as biomassbased materials derived from wood $^{\mathbf{4 3}}$ or prawn shells, ${ }^{\mathbf{4 4}}$ ordered mesoporous carbons (OMCs) ${ }^{45,46}$ or oxidised activated carbon fibres (ACFs). ${ }^{47}$ However, the specific capacitances of $\mathrm{M}$ 750 and M-900 were comparable or even higher than those of the aforementioned materials from the literature. ${ }^{44}$

From CV and GCD experiments, some contrasted results should be noticed. On one hand, M-750 and M-900 showed the highest specific capacitances at low scan rates and current densities (see Fig. 4b and 5b) despite the fact that they possessed the lowest specific surface areas $\left(8\right.$ and $102 \mathrm{~m}^{2} \mathrm{~g}^{-1}$, respectively) and low electrical conductivities ( 0.015 and $2.006 \mathrm{~S}$ $\mathrm{cm}^{-1}$, respectively). On the other hand, $\mathrm{SH}-900$ exhibited both the highest surface area $\left(562 \mathrm{~m}^{2} \mathrm{~g}^{-1}\right)$ and the highest electrical conductivity $\left(13.8 \mathrm{~S} \mathrm{~cm}^{-1}\right)$ but one of the lowest specific capacitances (Fig. $4 \mathrm{~b}$ and $5 \mathrm{~b}$ ).

Given that most of the porosity may be inaccessible to ions and given the different pseudocapacitance contributions to the total capacitances, the surface chemistry of the carbon samples clearly appears to be the key factor for explaining their different observed electrochemical performances. Therefore, the interfacial capacitances $\left(C / A_{\mathrm{BET}}\right.$ and $\left.C / S_{\mathrm{NLDFT}}\right)$ were calculated by dividing the specific capacitances obtained at $0.1 \mathrm{~A} \mathrm{~g}^{-1}$ by the surface areas obtained through the BET and NLDFT methods. The interfacial capacitance gives information about the materials' pseudocapacitance, the latter being directly proportional to the heteroatom content. ${ }^{48}$

$C / A_{\mathrm{BET}}$ and $C / S_{\mathrm{NLDFT}}$ values were thus plotted together versus the content of surface oxygen groups of the samples, and the resultant trends are displayed in Fig. 6. No significant correlation was found between the interfacial capacitances and the small amount of nitrogen groups detected at the surface of $\mathrm{MH}$ 750 and $\mathrm{MH}-900$, so it is not possible to determine if they participate in pseudocapacitive processes. The insoluble sulphates and sulphides are not believed to contribute to the pseudocapacitance of the different electrodes.

As commented above, the BET method underestimates the surface area of materials with narrow micropores. Previous 

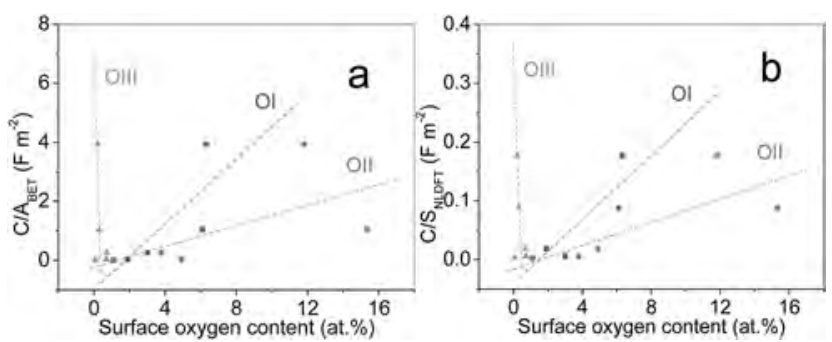

Fig. 6 Variation of interfacial capacitance, $C / A_{B E T}$ (a) and $C / S_{\text {NLDFT }}$ (b), as a function of surface concentration of oxygen functional groups: OI (quinones, carbonyls), OII (phenols, ethers, esters and anhydrides) and OIII (esters, anhydrides and carboxylic acids).

studies dealing with the accessibility of aqueous electrolytes to micropores indicated that pores smaller than $0.5 \mathrm{~nm}$ could accommodate neither $\mathrm{N}_{2}$ molecules nor simple hydrated ions at low rates. ${ }^{49}$ Since the main pore diameter of the studied samples is $\sim 0.5 \mathrm{~nm}, A_{\mathrm{BET}}$ could be considered in this case as a more appropriate estimation of surface area in order to determine the interfacial capacitance. Although Fig. $6 \mathrm{a}$ and $\mathrm{b}$ show a direct relationship between the surface concentration of OI and OII oxygen groups (namely quinones, carbonyls, phenols, ethers, esters and anhydrides) and $C / A_{\mathrm{BET}}$, the correlation coefficients are higher when using $C / S_{\mathrm{NLDFT}}$. Thus, it seems that interfacial capacitance may be better defined in terms of $S_{\mathrm{NLDFT}}$ for samples exhibiting porosities mainly composed of narrow pores (size $<0.7 \mathrm{~nm}$ ). This affirmation is in agreement with the results shown above, but it should be confirmed by studying a much larger number of samples. Keeping this in mind, Fig. $6 \mathrm{~b}$ could indicate that increasing OI and OII surface concentrations produced enhanced capacitances. The surface concentration of OIII groups showed no clear and probably negligible effects on the normalised capacitance values.

As stressed by these results, certain oxygen functional groups might account for the outstanding pseudocapacitive behaviour of the molasses-derived samples, M-750 and M-900, such as quinones, carbonyls, phenols, ethers, esters and anhydrides. Their participation to faradaic reactions related to pseudocapacitance has been already reported. ${ }^{42,50}$ Among them, quinones and carbonyl groups were proved to enhance the pseudocapacitance in $\mathrm{H}_{2} \mathrm{SO}_{4}$ electrolyte ${ }^{50}$ and might account for the high pseudocapacitive character of the molasses-based materials studied in this work.

\section{Conclusions}

Carbon materials obtained from sugarcane molasses either by HTC and subsequent carbonisation or by direct carbonisation exhibit low surface areas. Their porosities mainly comprise ultramicropores of size $\sim 0.5 \mathrm{~nm}$ that are hardly accessible to electrolyte ions. These materials exhibit high oxygen concentrations, about 7.5 at $\%$ at the surface of the HTC-derived carbons and 18-21 at\% at the surface of directly carbonised molasses. Despite their poorly developed porosities, the carbons obtained by direct carbonisation of molasses yielded high capacitances in $1 \mathrm{M} \mathrm{H}_{2} \mathrm{SO}_{4}$ electrolyte, reaching $153 \mathrm{~F} \mathrm{~g}^{-1}$ at $0.5 \mathrm{mV} \mathrm{s}^{-1}$ in a three-electrode cell and $32 \mathrm{~F} \mathrm{~g}^{-1}$ at $0.1 \mathrm{~A} \mathrm{~g}^{-1}$ in a two electrode-cell. This is explained by the high pseudocapacitance contribution of these samples, which is $35.2 \%$ in the molasses sample carbonised at $750{ }^{\circ} \mathrm{C}$. Such high pseudocapacitances are related to the considerable amount of surface oxygen functionalities, especially quinones and carbonyl functional groups. Meso-structuration and/or activation of molasses materials might be useful strategies to improve their porosities and achieve higher electrochemical performances.

\section{Acknowledgements}

The IJL research team gratefully acknowledges the financial support of the CPER 2007-2013 "Structuration du Pôle de Compétitivité Fibres Grand'Est" (Competitiveness Fibre Cluster), through local (Conseil Général des Vosges), regional (Région Lorraine), national (DRRT and FNADT) and European (FEDER) funds. Part of this work was supported by CHEERS project (FEDER funds). Dr A. Sanchez-Sanchez acknowledges the University of Lorraine and the Region Lorraine for financing her post-Doctoral contract.

\section{References}

1 J. R. Miller and P. Simon, Science, 2008, 321, 651-652.

2 P. Simon and Y. Gogotsi, Nat. Mater., 2008, 7, 845-854.

3 F. Beguin, V. Presser, A. Balducci and E. Frackowiak, Adv. Mater., 2014, 26, 2219-2251.

4 E. Frackowiak, Q. Abbas and F. Béguin, J. Energy Chem., 2013, 22, 226-240.

5 W. Gu, M. Sevilla, A. Magasinski, A. B. Fuertes and G. Yushin, Energy Environ. Sci., 2013, 6, 2465.

6 M. Zhou, F. Pu, Z. Wang and S. Guan, Carbon, 2014, 68, 185194.

7 X. Yu, H. J. Kim, J.-Y. Hong, Y. M. Jung, K. D. Kwon, J. Kong and H. S. Park, Nano Energy, 2015, 15, 576-586.

8 J. P. Paraknowitsch and A. Thomas, Energy Environ. Sci., 2013, 6, 2839.

9 D. Hulicova-Jurcakova, A. M. Puziy, O. I. Poddubnaya, F. Suárez-García, J. M. D. Tascón and G. Q. Lu, J. Am. Chem. Soc., 2009, 131, 5026-5027.

10 D. M. Anjos, J. K. McDonough, E. Perre, G. M. Brown, S. H. Overbury, Y. Gogotsi and V. Presser, Nano Energy, 2013, 2, 702-712.

11 Y. J. Oh, J. J. Yoo, Y. I. Kim, J. K. Yoon, H. N. Yoon, J.-H. Kim and S. B. Park, Electrochim. Acta, 2014, 116, 118-128.

12 A. Sánchez-Sánchez, F. Suárez-García, A. Martínez-Alonso and J. M. D. Tascón, Carbon, 2013, 62, 193-203.

13 L. Wei, M. Sevilla, A. B. Fuertes, R. Mokaya and G. Yushin, Adv. Energy Mater., 2011, 1, 356-361.

14 M.-M. Titirici, in Novel Carbon Adsorbents, Elsevier, Oxford, 2012, pp. 351-399, DOI: 10.1016/B978-0-08-097744-7.000120.

15 C. Long, L. Jiang, X. Wu, Y. Jiang, D. Yang, C. Wang, T. Wei and Z. Fan, Carbon, 2015, 93, 412-420.

16 P. Kleszyk, P. Ratajczak, P. Skowron, J. Jagiello, Q. Abbas, E. Fracckowiak and F. Béguin, Carbon, 2015, 81, 148-157. 
17 Y.-J. Ou, C. Peng, J.-W. Lang, D.-D. Zhu and X.-B. Yan, New Carbon Mater., 2014, 29, 209-215.

18 W. Feng, P. He, S. Ding, G. Zhang, M. He, F. Dong, J. Wen, L. Du and M. Liu, RSC Adv., 2016, 6, 5949-5956.

19 J. Hou, C. Cao, X. Ma, F. Idrees, B. Xu, X. Hao and W. Lin, Sci. Rep., 2014, 4, 7260.

20 M. Sevilla and A. B. Fuertes, Carbon, 2009, 47, 2281-2289.

21 P. Kim, J. B. Joo, W. Kim, J. Kim, I. K. Song and J. Yi, Catal. Lett., 2006, 112, 213-218.

22 K. S. W. Sing, in Adsorption by Carbons, ed. J. M. D. Tascón, Elsevier, Amsterdam, 2008, pp. 3-14, DOI: 10.1016/B978008044464-2.50005-5.

23 J. H. Scofield, J. Electron Spectrosc. Relat. Phenom., 1976, 8, 129-137.

24 M. Thommes, K. A. Cychosz and A. V. Neimark, in Novel Carbon Adsorbents, Elsevier, Oxford, 2012, pp. 107-145, DOI: 10.1016/B978-0-08-097744-7.00004-1.

25 C. L. Burket, R. Rajagopalan, A. P. Marencic, K. Dronvajjala and H. C. Foley, Carbon, 2006, 44, 2957-2963.

26 A. Kurniawan, L. K. Ong, F. Kurniawan, C. X. Lin, F. E. Soetaredjo, X. S. Zhao and S. Ismadji, RSC Adv., 2014, 4, 34739-34750.

27 J. L. Figueiredo, M. F. R. Pereira, M. M. A. Freitas and J. J. M. Órfão, Carbon, 1999, 37, 1379-1389.

28 J. Adánez, V. Fierro, J. A. de Diego, L. F. de Diego and F. García-Labiano, Thermochim. Acta, 1996, 277, 151-164.

29 U. Golla-Schindler, G. Benner, A. Orchowski and U. Kaiser, Microsc. Microanal., 2014, 20, 715-722.

30 Y. Zhou, S. L. Candelaria, Q. Liu, Y. Huang, E. Uchaker and G. CaO, J. Mater. Chem. A, 2014, 2, 8472-8482.

31 K. T. Cho, S. B. Lee and J. W. Lee, J. Phys. Chem. C, 2014, 118, 9357-9367.

32 E. M. Van der Merwe, C. A. Strydom and J. H. Potgieter, Thermochim. Acta, 1999, 340-341, 431-437.

33 M. E. Labib, J. H. Thomas III and D. D. Embert, Carbon, 1984, 22, 445-451.
34 W. Q. Hull, F. Schon and H. Zirngibl, Ind. Eng. Chem., 1957, 49, 1204-1214.

35 D. Briggs, Surface Analysis of Polymers by XPS and Static SIMS, Cambridge University Press, 1998.

36 D. Briggs and J. T. Grant, Surface analysis by Auger and X-ray photoelectron spectroscopy, IM Publications, Chichester, 2003.

37 A. B. Dongil, B. Bachiller-Baeza, A. Guerrero-Ruiz, I. Rodriguez-Ramos, A. Martinez-Alonso and J. M. Tascon, J. Colloid Interface Sci., 2011, 355, 179-189.

38 M.-M. Titirici, M. Antonietti and N. Baccile, Green Chem., 2008, 10, 1204-1212.

39 D. Pantea, H. Darmstadt, S. Kaliaguine and C. Roy, J. Anal. Appl. Pyrolysis, 2003, 67, 55-76.

40 Y. Xia and R. Mokaya, Adv. Mater., 2004, 16, 1553-1558.

41 H. Shi, Electrochim. Acta, 1996, 41, 1633-1639.

42 T. A. Centeno and F. Stoeckli, Electrochim. Acta, 2011, 56, 7334-7339.

43 R. Asakura, T. Kondo, M. Morita, H. Hatori and Y. Yamada, Tanso, 2004, 2004, 231-235.

44 F. Gao, J. Qu, Z. Zhao, Z. Wang and J. Qiu, Electrochim. Acta, 2016, 190, 1134-1141.

45 A. B. Fuertes, G. Lota, T. A. Centeno and E. Frackowiak, Electrochim. Acta, 2005, 50, 2799-2805.

46 C. Vix-Guterl, E. Frackowiak, K. Jurewicz, M. Friebe, J. Parmentier and F. Béguin, Carbon, 2005, 43, 1293-1302.

47 H. Oda, A. Yamashita, S. Minoura, M. Okamoto and T. Morimoto, J. Power Sources, 2006, 158, 1510-1516.

48 U. B. Nasini, V. G. Bairi, S. K. Ramasahayam, S. E. Bourdo, T. Viswanathan and A. U. Shaikh, J. Power Sources, 2014, 250, 257-265.

49 J. Koresh and A. Soffer, J. Electroanal. Chem. Interfacial Electrochem., 1983, 147, 223-234.

50 D. Hulicova-Jurcakova, M. Seredych, G. Q. Lu and T. J. Bandosz, Adv. Funct. Mater., 2009, 19, 438-447. 